\title{
INDICATORS FOR RESOURCE ALLOCATION IN THE HEALTH SYSTEM - A REGIONAL APPROACH
}

\author{
Maria Rohova \\ Department of Economics and Health Care Management, Faculty of Public Health, \\ Medical University of Varna
}

\begin{abstract}
INTRODUCTION: Resource allocation is closely related to the health inequalities issue and is an important anchor for reducing the inequities in the health system. Its basic principles include effectiveness, equity and utility. The aim of this study is to propose a system of indicators for Bulgarian health system, which could be used for resource allocation in the health care.

MATERIALS AND METHODS: This study relies on a qualitative method, namely an expert opinion research. The inquiry was conducted at the end of 2014 and includes 41 experts in the field of health care in Bulgaria. The results are summarised and analysed by median and percentiles.

RESULTS AND DISCUSSION: The results confirm the relationship between health inequalities, health inequities and resource allocation and the connection is the access to health services. Distribution of the resources in the health system should be based on the specific health needs of the population at a regional level. As a result of the expert opinion, a system of indicators for resource allocation is composed. It can be used for resource allocation in Bulgarian health care. The system has two main groups of indicators - for resource allocation among regions and for distribution of resources between health services, programmes and health sectors in one region. The indicators are summarised in 5 categories - general characteristics of the region, demographic, socio-economic, ecological characteristics and health status variables.
\end{abstract}

CONCLUSIONS: Fair and equitable resource allocation among regions is an important instrument for reducing health inequities. But for improving the access to health services, all decisions have to consider population health needs, so the health system will be "patient-centred".

Keywords: resource allocation, indicators, health equity, region

Address for correspondence:

Maria Rohova

55 Marin Drinov St.

Faculty of Public Health

Medical University of Varna

9002, Varna

BULGARIA

e-mail: mariarohova@abv.bg

Received: September 18, 2016

Accepted: November 24, 2016

\section{INTRODUCTION}

Resource allocation is a process of distributing resources between competing claims (population groups, health programs, health sectors or health care establishments, regions) to meet certain specified goals (6). Usually it concerns allocation of financial resources, but it can be attributed to all other types of resources. In general, the allocation of funds is connected to 3 decision levels: (i) distribution between health care and other social sectors; (ii) distribution 
between different sectors within health care; and (iii) distribution between different patient groups. These decisions are taken at national level and they refer to supply of health services. The allocation process is driven from trends towards efficiency and equity in health care (3).

According to Sheldon and Smith (2000), resource allocation is one of the most disputable challenges in health care. It is closely related to the health inequalities issue and is an important anchor for reducing the inequities in health system. In this regard, resource allocation depends on the interpretation of health equity - equal opportunities for access to health services or equal chances of people to be healthy. In the first case, the allocation depends on morbidity and provision of equal services for equal needs; in the second - the distribution should mitigate the gaps between the most favorable and the most vulnerable population groups.

The basic principles of resource allocation can be summarised as follows (6):

1. Active resource allocation is driven by the need to achieve efficiency and equity in healthcare provision.

2. Risk-adjusted capitation is the most common method used internationally. Risk adjustment should reflect health needs.

3. Identification of needs should be based on available epidemiological and scientific data rather than apparent health care expenditure or utilisation information.

4. Equitable resource allocation is imperative if the model is to be widely accepted.

The World Health Organisation (WHO) has defined ethical principles of resource allocation, which include effectiveness (maximising the benefits for population health), equity (minimising the differences between population groups), and utility (7). The implementation of these principles requires regular assessment and active involvement of stakeholders.

There is a great diversity of variables applied in resource allocation models. Despite this variety, the most used variables (especially in countries-members of the Organisation for Economic Co-operation and Development) can be summarised as follows (2):

\section{Demographic variables}

$\diamond$ sex and age - every model includes age as a variable, which predicts health needs. Sex is not so often used because the different regions have similar male-female ratio. In many countries, there are evidence-based data about the relationship between sex, age, and health services utilisation;

$\diamond$ ethnicity - variables such as race, citizenship, and country of birth are used in resource allocation models (for example, in New Zealand and in Sweden);

$\diamond$ health status variables - morbidity, mortality, disability, etc.

2. Socio-economic variables - usually the models include occupation (for example, in the United Kingdom and in Sweden) and social status (for example, in Sweden), which are considered as tightly related to the utilisation of health services. Other socio-economic variables such as education, profession, income and consumption are rarely used due to lack of data in the short run. Furthermore, education, profession and income are viewed as interrelated and the models are usually built only with one of these variables (for example, in Sweden).

3. Geographical variables - they can explain variations in some aggregate variables (as mortality or morbidity), as well as the effect of some demographic and socio-economic variables. Moreover, in different regions, health service provision is different and the costs also vary (for example, in the United Kingdom).

The aim of this study is to propose a system of indicators, which could be used for resource allocation in Bulgarian health care (social health system with universal coverage). In addition to this, the study investigates the relationship between health inequalities, health inequities and resource allocation, based on the health care experts' opinion.

\section{MATERIALS AND METHODS}

This study relies on a qualitative method, namely an expert opinion research, using semistructured interview as a method for information collection. The interview was conducted at the end of 2014 in Bulgaria. 
A crucial moment in qualitative research is the selection of the experts. The qualitative research does not have representative character; its purpose is to receive competent expert opinion $(1,4) .60$ experts in health care in Bulgaria were invited to participate in the study, including: researchers in health care, managers of health care establishments, head nurses in hospitals, representatives of the National Health Insurance Fund, Regional Health Insurance Funds, Regional Health Inspectorates, municipalities, professional organisations, and nongovernment organisations in health care. These are representatives of important stakeholders in the Bulgarian health system.

From all invited experts, 41 took part in the inquiry. They are representatives of all stakeholders except municipalities, so the results can be interpreted as significant from an expert point of view. The inquiry includes two groups of questions regarding:

$\diamond$ expert opinion about the relationship between health inequalities, health inequities and resource allocation in health care - Likert scale is used;

$\diamond$ identifying the indicators, which can be used for resource allocation between regions (districts) in the country and between health sectors, services and programs in the regions (districts). The results are summarised and analysed by median and percentiles.

\section{RESULTS AND DISCUSSION}

Several statements about the relationship between inequities in access to health services, health inequalities, and resource allocation are formulated and included in the inquiry (Table 1). For each statement, the experts should point out their level of agreement or disagreement. Likert scale with 5 possible answers is used (Table 1).

The results confirm the relationship between health inequalities, health inequities, and resource allocation and the connection is the access to health services. Distribution of resources in the health system should be based on specific health needs of the population at a regional level. Thus, the resource allocation should be implemented on two levels - on one hand, among regions (districts) in the country, and on the other hand, between health programmes, sectors or services, and population groups in the region.

Existing disproportions between districts in the country hinder the access to health services in some regions and in smaller settlements, so the fair resource allocation based on the health needs and regional particularities can contribute to reducing access barriers and thus, health inequities.

The next part of the inquiry concerns indicators, which should be taken into account by resource allocation in the health system. Based on existing allocation models in other countries, a list with

Table 1. Expert opinion about health inequities and resource allocation

\begin{tabular}{|c|c|c|c|c|c|}
\hline Statements & $\begin{array}{l}\text { Strongly } \\
\text { agree }\end{array}$ & Agree & Neutral & Disagree & $\begin{array}{l}\text { Strongly } \\
\text { disagree }\end{array}$ \\
\hline $\begin{array}{l}\text { 1. In resource allocation, regional particu- } \\
\text { larities and health needs of the population in } \\
\text { the region should be taken into account. }\end{array}$ & $65.85 \%$ & $34.15 \%$ & - & - & - \\
\hline $\begin{array}{l}\text { 2. The starting point of resource allocation } \\
\text { in the health system should be the region } \\
\text { (district). }\end{array}$ & $43.90 \%$ & $39.02 \%$ & $12.20 \%$ & $4.88 \%$ & - \\
\hline $\begin{array}{l}\text { 3. To reduce health inequities, barriers in ac- } \\
\text { cess to health services should be removed. }\end{array}$ & $53.66 \%$ & $36.58 \%$ & $7.32 \%$ & $2.44 \%$ & - \\
\hline $\begin{array}{l}\text { 4. If the access to health services is improved } \\
\text { at regional level, the inequalities in health } \\
\text { status can be reduced. }\end{array}$ & $36.58 \%$ & $53.66 \%$ & $9.76 \%$ & - & - \\
\hline $\begin{array}{l}\text { 5. Fair resource allocation among regions is } \\
\text { of the crucial importance for improving the } \\
\text { access to health services. }\end{array}$ & $39.02 \%$ & $58.54 \%$ & $2.44 \%$ & - & - \\
\hline
\end{tabular}


possible variables has been formulated. The experts were invited to point out which indicators should be included in the distribution of resources among regions (districts) and which are important for the distribution between different health sectors (health promotion and prevention, outpatient and inpatient care, primary and specialised care, etc.) in one region (district). The answers are interpreted as specific "vote" of the experts and every proposed indicator receives a definite number of polls. According to these polls, the decision about which indicators could be used for resource allocation is made. Some of the included indicators have not been chosen by the experts. Moreover, the experts proposed additional indicators.

Analyses of the results are made with median and $25^{\text {th }}$ and $75^{\text {th }}$ percentiles. As a value separating the higher half of a data sample, the median in this case is 21 or every indicator which has 21 or more "votes" falls into the upper half. We use also the $25^{\text {th }}$ percentile which is even to 11 and $75^{\text {th }}$ percentile which is 31 . Our decision is to include in the system these indicators, which have collected more than $50 \%$ of the experts "votes", i.e. are above the median. They are presented in Table 2. The indicators are summarised in 5 sections - general characteristics of the region, demographic, socio-economic, ecological characteristics, and health status variables. Two additional indicators are defined as well.

Additionally, the experts proposed several indicators, which can be used for resource allocation among regions (districts) in the country:

$\diamond$ population age structure (in the region and in different settlements) - this indicator is important since it is related to the health needs of the population. Together with the indicator "proportion of ageing population", age structure has been included in the system of indicators;

$\diamond$ educational structure and health culture of the population - this indicator is of great importance for health promotion and conducting screening campaigns, so it is taken into account, but not at regional level;

$\diamond$ hospital admissions in the region - the inclusion of such indicator could distort or manipulate the results since it is more of a consequence, than a predictor of the population health needs.
Nevertheless, it could be used, but only as correction for hospital care.

In addition to the suggested indicators for distribution of resources between different health sectors, health services, and health programmes in one region, the experts proposed several other indicators:

$\diamond$ chronic diseases in the region - this indicator together with "proportion of population with disability" will make the assessment more precise and more closely related to the population health needs for specialised medical care;

$\diamond$ mortality in different age groups - the indicator is connected with the so-called amendable mortality and curable morbidity. The last two indicators can be much more useful for resource allocation among regions and between health sectors. However, data for these indicators are not available in Bulgaria, so additional studies need to be performed;

$\diamond$ population age structure (in the region and in different settlements) - we accept this indicator as important for distribution of resources between health sectors and services in one region. Included in the system of indicators, it could contribute to the assessment of health needs in the region;

$\diamond$ birth rate in the region - there are solid grounds to include this indicator in the system. It gives an idea of the needs for obstetric and paediatric health services in specialised outpatient and inpatient care. Besides, maternal and child health is one of the priorities in the national health system - a fact, which also should be taken into account by building the system of indicators.

As a result of the analyses, the system of indicators for resource allocation is composed. The system has two main groups of indicators - for resource allocation among regions and for distribution of resources between health services, programmes and health sectors in one region (Table 2). The system includes these indicators, which have more than $50 \%$ of the "votes" of the experts (or which are above the median) and several other indicators, suggested by the experts. 
Table 2. Indicators for resource allocation in the health system

Resource allocation among regions (districts) in the country

General characteristics of the region, settlements, and infrastructure

Number of settlements in the region

Type of settlements - cities, towns, and villages

Number of settlements with population up to 100 people

Urban to rural population proportion

Geographical peculiarities of the region - relief

Distance to a hospital for active treatment

Distance to a centre for emergency care

Distance to a primary care practice

Infrastructure conditions

\section{Demographic characteristics of the region}

Size of the population in the region

Population density in the region

Life expectancy in the region

Age structure of the population in the region (total and in different settlements)

Proportion of the ageing population

Mortality in the region

\section{Socio-economic development of the region}

Gross domestic product per capita in the region

Unemployment in the region

Average income in the region

Population with income below the poverty line

\section{Health status}

Infant mortality

Proportion of people with disability

Total morbidity in the region

\section{Ecological characteristics in the region}

Characteristics of industrial development

Environmental characteristics

\section{Additional indicators}

Amenable morbidity (mortality)

Curable morbidity (mortality)

The last two indicators are additional because there is no such data in Bulgaria and more studies
Resource allocation between health sectors, health services and programs in one region (district)

General characteristics of the region, settlements, and infrastructure

Distance to the district centre

Distance to a hospital for active treatment

Distance to a primary care practice

Distance to a centre for emergency care

Demographic characteristics of the region

Age structure of the population in the region (total and in different settlements)

Life expectancy in the region

Proportion of the ageing population

Birth rate in the region

Mortality in the region

Age group mortality

\section{Health status}

Maternal mortality

Infant mortality

Proportion of persons with disability

Mortality by causes

Total morbidity in the region

Morbidity by causes

Communicable diseases in the region

Chronic diseases

Ecological characteristics in the region

Characteristics of industrial development

are needed. 


\section{CONCLUSIONS}

Based on the results of the expert inquiry, a system of indicators has been composed. It could be used for resource allocation in the Bulgarian health system. The two groups of indicators are intended for distribution of resources among regions in the country and between health sectors (health promotion, outpatient and inpatient care, primary and specialised care, etc.) in one region and could be useful for preparation of national and regional health maps. The implementation of the system of indicators needs some additional studies to determine the values of indicators in the different regions of the country. On this ground, a scale with variations of indicators could be composed. The quantitative assessments are the basis for creating specific formulas for distribution of financial resources in the health system.

By resource allocation, several characteristics should be taken into account, namely specific characteristics of the region, its population and infrastructure, socio-economic development, ecological characteristics, health status of the population, each of these influencing health needs.

Fair and equitable resource allocation among regions is an important instrument for reducing health inequities. But for improving the access to health services, all decisions have to consider population health needs, so the health system will be "patient-centred".

\section{REFERENCES}

1. Denzin NK, Lincoln YS (Eds.) The Sage Handbook of Qualitative Research. $3^{\text {rd }}$ ed., Thousand Oaks, London; 2005.

2. Diderichsen F. Resource Allocation for Health Equity: Issues and Methods. The World Bank, Washington; 2004.

3. Gladilov S, Delcheva E. Health Economics. Princeps, Sofia; 2000 (in Bulgarian).

4. Marvasti AB. Qualitative Research in Sociology. An Introduction. Sage Publications, London; 2004.

5. Sheldon TA, Smith PC. Equity in the Allocation of Health Care Resources. Health Economics, 2000, 9:571-4.

6. Vega A, O'Shea S, Murrin C, Staines A. Towards the Development of a Resource Allocation Model for Primary Continuing and Community Care in the Health Services. Technical Report, Vol. 2, Dublin; 2010.

7. WHO. Guidance on Ethics and Equitable Access to HIV Treatment and Care, 2004. Available from: http://www.who.int/ethics/Guidance\%20on\%20 Ethics\%20and\%20HIV.pdf. 